\title{
High Resolution DNA Melting Assays for Detection of Rx1 and Rx2 for High-Throughput Marker-Assisted Selection for Extreme Resistance to Potato virus $X$ in Tetraploid Potato
}

\begin{abstract}
Xianzhou Nie ${ }^{\dagger}$ and Virginia L. Dickison, Fredericton Research and Development Centre, Agriculture and Agri-Food Canada, Fredericton, NB, E3B 4Z7, Canada; Sydney Brooks, Fredericton Research and Development Centre, Agriculture and Agri-Food Canada, Fredericton, NB, E3B 4Z7, Canada; and Department of Biochemistry and Microbiology, University of Victoria, Victoria, BC, V8P 5C2, Canada; Bihua Nie, Fredericton Research and Development Centre, Agriculture and Agri-Food Canada, Fredericton, NB, E3B 4Z7, Canada; and MOA Key Laboratory of Potato Biology and Biotechnology, Potato Engineering and Technology Research Center of Hubei Province, and Huazhong Agricultural University, Wuhan 430070, China; Mathuresh Singh, Agricultural Certification Services, Fredericton, NB, E3B 8B7, Canada; David L. De Koeyer, Fredericton Research and Development Centre, Agriculture and Agri-Food Canada, Fredericton, NB, E3B 4Z7, Canada; and International Institute of Tropical Agriculture, Ibadan 200001, Oyo State, Nigeria; and Agnes M. Murphy, Fredericton Research and Development Centre, Agriculture and Agri-Food Canada, Fredericton, NB, E3B 4Z7, Canada
\end{abstract}

\begin{abstract}
Assessment of the existing PCR-gel electrophoresis-based methods for detection of $R x 1$ and $R x 2$, the genes that independently control extreme resistance (ER) to Potato virus $X(\mathrm{PVX})$, indicated that the $5 \mathrm{Rx} 1 \mathrm{~F} /$ $5 \mathrm{Rx} 1 \mathrm{R}$ primer pair led to reliable detection of $R x l$, whereas the 106Rx2F/106Rx2R primer pair detected $R x 2$ despite some nonspecific reactions in potato clones/cultivars without $R \times 2$. However, the methodology is time consuming and does not differentiate the absence of $R \times 1 / R \times 2$ from a failed PCR reaction. A newly designed primer pair that targets $R x l$ and $R x 2$ as well as $r x 1$ and $r x 2$ produced an amplicon for all alleles. When the primer pair was combined with $5 \mathrm{R} x 1 \mathrm{~F} / 5 \mathrm{R} x 1 \mathrm{R}$, respective amplicons were produced, although they were not distinguishable by regular agarose gel electrophoresis. When subjected to a high-resolution DNA

melting (HRM) assay, two distinct melting profiles for $R x 1$ and $r x 1$, respectively, were detected. Triplex PCR-gel electrophoresis and -HRM assay for detection of $R x 1, R x 2$, and $r x 1 / r x 2$ were also performed. The efficacy of the HRM assays were validated in potato cultivars/clones with known phenotypes, indicating its potential for high-throughput selection of potato clones/cultivars carrying $R \times 1$ or $R \times 2$. Duplex PCR-HRM assays of over 600 progeny from 12 crosses involving various parents correctly detected the presence or absence of $R x l$ in each progeny, allowing accurate prediction of the phenotype. Progeny that tested positive for $R x l$ by HRM exhibited ER to PVX whereas progeny that tested negative for $R x I$ were susceptible to PVX infection. The genotype of each parent and the possible presence of $N x$ in two $R x 1$-possessing parents are also discussed.
\end{abstract}

Potato virus X(PVX, genus Potexvirus, family Alphaflexiviridae) is one of the most common and economically important viruses affecting potato production worldwide. It causes symptoms ranging from latent to mild mosaic, and occasionally severe top necrosis depending on potato cultivars (Cockerham 1943; Hooker et al. 1954). The most striking disease associated with PVX is the so-called PVX/potyviral synergistic disease, a condition that occurs when plants are infected with both PVX and a potyvirus such as Potato virus A (PVA) or Potato virus $Y$ (PVY) (MacLachlan et al. 1954; Nie and Singh 2013). Potato crinkle disease caused by the mixed infection of PVX/PVA is the best known example of PVX/potyviral synergistic disease (MacLachlan et al. 1954). The disease is significantly more severe than that caused by single infections with either PVX or PVA. Mixed infection of potato cv. Kennebec with PVX and PVYNTN results in premature plant death, whereas single infection with either virus only causes mosaic on the plants (Nie and Singh 2013).

As a mechanically transmitted virus, PVX can be readily spread in the field through plant contact and crop management operations. The control/management of PVX mainly relies on phytosanitary measures, flush-through seed multiplication schemes, and the use of resistant cultivars. Two $R$ genes, namely $R x 1$ and $R x 2$, have been identified and isolated in potato (Bendahmane et al. 1999, 2000). $R x l$ is located on chromosome 12, whereas $R x 2$ is on chromosome 5 (Bendahmane

${ }^{\dagger}$ Corresponding author: Xianzhou Nie; E-mail: xianzhou.nie@agr.gc.ca

*The $\boldsymbol{e}$-Xtra logo stands for "electronic extra" and indicates that two supplementary figures are published online.

Accepted for publication 29 September 2017.

() Her Majesty the Queen in Right of Canada, as represented by the Minister of Agriculture and Agri-Food Canada, 2018 et al. 1997, 1999, 2000). The former (also known as $R x_{a d g}$ ) is derived from Solanum tuberosum subsp. andigena (Bendahmane et al. 1997; Querci et al. 1995; Ritter et al. 1991), and the latter (also known as $R x_{a c l}$ ) originated from $S$. acaule (Bendahmane et al. 2000; Brown and Corsini 2001; Ritter et al. 1991). Each of the two $R x$ genes independently confers extreme resistance (ER) to PVX. The $R x$ genes have been introgressed into potato breeding programs worldwide, thus leading to the release of numerous potato clones/cultivars with ER to PVX. A number of commercially important cultivars grown in Canada and the U.S.A., including Atlantic, Saco, and Jemseg, are presumed to possess $S$. tuberosum subsp. andigena-derived ER to PVX (Brown and Corsini 2001). In Agriculture and Agri-Food Canada (AAFC)'s potato breeding program, many potato breeding clones exhibit ER to PVX infection. However, it remains unknown which of the two $R x$ genes exist in the clones, and the selection for PVX-ER still relies on labor-intensive phenotyping tests in the greenhouse.

Marker-assisted selection (MAS) for desirable traits has been utilized in many different crops including potatoes $(\mathrm{Xu}$ and Crouch 2008). It offers several advantages including efficiency and accuracy over the conventional phenotype-based selection (Nie et al. 2016). However, the efficiency and accuracy of MAS rely on the type of marker and the marker's linkage level to the traits. For instance, gel electrophoresis-based MAS assays are time consuming and laborious, which make these markers less efficient than those that can be detected with gel electrophoresis-free methods. This is demonstrated by the dramatic increase in efficiency of high resolution DNA melting (HRM) assay over the gel electrophoresis-based assay for markers linked to $R y_{\text {sto }}$ (Nie et al. 2016).

Several markers, including the PCR marker 221R (Kanyuka et al. 1999) and the cleaved amplified polymorphic sequence (CAPS) markers 218R (AluI) (Kanyuka et al. 1999) and CP60 (DdeI) (Bendahmane et al. 1997), have been developed and utilized for determination and/or selection for $R x$ and $R x$-mediated ER to PVX in potatoes (Gebhardt et al. 
2006; Heldák et al. 2009; Sathuvalli et al. 2016). Moreover, as both $R x 1$ and $R \times 2$ have been isolated, PCR assays using primers specific to the genes have been developed for their detection (Ahmadvand et al. 2013; Mori et al. 2011). However, these PCR assays have not yet been evaluated with large numbers of samples, especially in segregating populations; therefore, it is unknown whether these assays can be performed using the more efficient and robust HRM assay.

The objectives of this study were 1) to assess the efficacy of PCR procedures reported by Mori et al. (2011) and Ahmadvand et al. (2013) for detection of $R x 1$ and $R x 2$ in potato germplasm, 2) to develop HRM assay for $R x 1$ and $R \times 2$ genes in potato plants, 3 ) to determine the $R x$ identity in potato clones exhibiting ER to PVX, and 4) to evaluate and validate the HRM assay for high-throughput MAS for progeny carrying $R x 1$ and/or $R x 2$ in segregating populations of tetraploid potato.

\section{Materials and Methods}

Plant materials. Forty-two (42) potato breeding clones/advanced selections whose resistance status to PVX had been identified by multiple assessments (mechanical and graft inoculations) by the breeding program at the Fredericton Research and Development Centre of Agriculture and Agri-Food Canada were used.

For assessment and validation of the HRM assays for markerassisted selection for progeny carrying $R x l$ gene, $\sim 720$ true botanical seeds of 12 crosses ( $\sim 60$ each of Atlantic [R] $\times$ F87031 [R]; Torridon $[\mathrm{R}] \times$ Redsen [R]; AC Domino [R] $\times$ AC Chaleur [S]; Atlantic [R] $\times$ F58089 [S]; F87084 [R] $\times$ F59103 [S]; Torridon [R] $\times$ AC Blue Pride [S]; F87084 [R] $\times$ Kanona [S]; AC Blue Pride [S] $\times$ Redsen [R]; F87084 [R] × F58050 [S]; Mirton Pearl [S] × Rochdale Gold-Dorée $[\mathrm{R}]$; AC Chaleur $[\mathrm{S}] \times$ F02010 [R]; NY121 [R] $\times$ ND860-02 [S]) were germinated in trays filled with Pro-Mix potting soil (Premier Horticulture Inc., Rivièredu-Loup, Quebec) under greenhouse conditions. The resulting seedlings were transplanted to 5-in. $(12.7-\mathrm{cm})$ pots containing Pro-Mix potting soil when they were $\sim 3 \mathrm{~cm}$ tall, and grown in the greenhouse with a light/dark cycle of $16 / 8 \mathrm{~h}$. The natural light was supplemented with artificial light or shade to give a light intensity of $\sim 90 \mu \mathrm{m}^{2} / \mathrm{s}$. The temperature was set at $24 / 18^{\circ} \mathrm{C}$ (day/night) with a humidity of $75 \%$ (Nie et al. 2016). When the plants reached the 4-leaf stage, total DNA was extracted from each of the progeny plant. When the plants reached the 6-leaf stage, they were mechanically inoculated with PVX.

DNA extraction. Qiagen DNeasy Plant Mini Kit method (Qiagen, Frederick, MD) and KingFisher DNA extraction protocol (Thermo Scientific KingFisher, Waltham, MA) were used for extraction of genomic DNA from potato cultivars/clones and progeny of 12 crosses, respectively. The former was performed as described previously (Nie et al. 2016). The latter is a robust method with the capacity to extract DNA from 96 samples on a KingFisher 96-well plate using MagBind Plant DNA DS 96 extraction kit (Omega Bio-Tek, Norcross, GA) employing the KingFisher Flex Purification System liquid handling apparatus (ThermoFisher Scientific, Waltham, MA). Briefly, young leaf tissue $(\sim 50 \mathrm{mg})$ taken from greenhouse grown plants were freeze dried and ground using the 2010 Geno/Grinder (SPEX Sample Prep, Metuchen, NJ). Ground tissue was extracted following the manufacturer's protocol (Mag-Bind Plant DNA DS 96 extraction kit, Omega Bio-Tek). A secondary wash step was utilized for further purification of the extracted DNA, as per manufacturer's recommendations, and eluted in $100 \mu$ l of elution buffer provided by Omega Bio-Tek. Following DNA extraction, the quality and quantity of DNA was analyzed using the Qubit Fluorometer (Invitrogen, Carlsbad, CA) and Nanodrop 2000 Spectrophotometer (ThermoFisher Scientific). The concentration of the DNA was adjusted to $10 \mathrm{ng} / \mu 1$.

PVX culture and inoculation. PVX-NB, a PVX isolate that is used as the standard for PVX detection for certification services in laboratories accredited by Canadian Food Inspection Agency, was used in this study. The virus was maintained in tobacco cv. Samsun in the greenhouse, and regularly verified for its purity by ELISA test prior to being used as virus culture/inoculum. For mechanical inoculation, leaves of the PVX culture were homogenized in an inoculation buffer $(10 \mathrm{mM}$ sodium phosphate buffer, $\mathrm{pH} 7.5$, with $32 \mathrm{mM}$ sodium sulphite) at 1:2 ratio (w/v). The top two leaves of potato test plants were dusted with Carborundum powder (400 mesh) and rubbed gently with a pestle in the presence of virus extract or inoculation buffer (mock). For graft-inoculation, a PVX-positive leaf or a small branch (scion) was top-grafted onto a potato plant (stock). Upon inoculation, the plants were kept in the greenhouse under the same conditions described above for approximately 2 months, and monitored for visual symptoms regularly. ELISA assays for PVX in the inoculated plants was performed 2 weeks postinoculation.

Enzyme-linked immunosorbent assay (ELISA). ELISA with PVX polyclonal antibodies (Adgen Phytodiagnostics, Neogen, Scotland, U.K.) was performed according to the manufacturer's instructions. A sample was considered positive when absorbance at $405 \mathrm{~nm}\left(\mathrm{~A}_{405}\right)$ was three times that of the negative (healthy) control with a reading of $A_{405} \geq 0.100$ (Nie et al. 2015). Samples whose $A_{405}$ fell between the criteria (i.e., $\geq$ three times of the healthy control and $<0.100)$ were retested by ELISA.

Real-time PCR, HRM, and gel electrophoresis analysis of PCR products. Thirty nanograms $(30 \mathrm{ng})$ of DNA template was used in the $10-\mu l$ reaction, along with $5 \mu l$ of the $2 \times$ Precision Melt Supermix containing EvaGreen dye (Bio-Rad Laboratories) and $0.2 \mathrm{mM}$ of each primer. The real-time PCR optimization was carried out using a 45 -cycle amplification, each beginning with $95^{\circ} \mathrm{C}$ for $10 \mathrm{~s}$, a gradient annealing temperature of 56 to $68^{\circ} \mathrm{C}$ for $30 \mathrm{~s}$, followed by $72^{\circ} \mathrm{C}$ for $30 \mathrm{~s}$. The optimum annealing temperature of $60^{\circ} \mathrm{C}$ was determined based on the lowest $\mathrm{Ct}$ value and specific amplification.

Following the establishment of suitable melt profiles for each genotype (i.e., $R x 1$ presence or absence, $R x 2$ presence or absence), each sample was evaluated individually with HRM analysis on multiple occasions to verify the reproducibility of the assay. The primer pairs used were RxSP-S3 (5'-ATCTTGGTTTGAATACATGG-3') + RxSP-A2 (5'-CACAATATTGGAAGGATTCA-3') (Mori et al. 2011), 5Rx1F (5'-TCAGGGCAAAACCCTAACAC-3') + 5Rx1R (5'-ATCGGCCTAGAGTGACATCG-3') (Ahmadvand et al. 2013), 106Rx2F (5'-GGAGAAATCCTGCAATGTAAC-3') + 106Rx2R (5'-CTTGTCAAAGAAAGAAGGCCT-3') (Ahmadvand et al. 2013), and Rx_S1584 (5'-AATGCGTCACACTGGAATTG-3') + Rx_A1756a (5'-TGAGGGAACAGCTTCTATCG-3') (this study). Real-time PCR conditions were followed as above using the CFX96 Real-Time System (Bio-Rad Laboratories) with a final extension of $72^{\circ} \mathrm{C}$ for $6 \mathrm{~min}$. The melt profile was determined by a $95^{\circ} \mathrm{C}$ denaturation step for $60 \mathrm{~s}$ prior to annealing at $55^{\circ} \mathrm{C}$ to ensure uniform annealing of all amplicons and then increasing the temperature by $0.2^{\circ} \mathrm{C}$ increments to $95^{\circ} \mathrm{C}$ with a 10 -s plate read at each temperature increase. The DNA melting profile of the progeny of 12 segregating populations was also performed on a 96-well LightScanner HRI96 (Idaho Technology Inc., Salt Lake City, UT) after $10 \mu$ l of mineral oil was overlaid on each sample. HRM conditions were identical as before $\left(55\right.$ to $\left.95^{\circ} \mathrm{C}\right)$; however, plate reads were taken at $0.1^{\circ} \mathrm{C}$ increments, allowing for further resolution. The melting data obtained from CFX96 and LightScanner were analyzed using Precision Melt Analysis Software (Bio-Rad Laboratories) and LightScanner Software v2.0 (Idaho Technology), respectively.

Agarose gel electrophoresis was performed on samples to determine the amplicon product(s). Ten (10) $\mu$ l PCR products were loaded onto a $1.5 \%$ agarose gel stained with Gel Red (Biotium Inc., Hayward, $\mathrm{CA})$. The presence or absence of the predicted amplicons were visualized and recorded with BioSpectrum Imaging System (UVP Inc., Upland, CA).

\section{Results}

Extreme resistance to PVX in tetraploid potato breeding clones. In potato, extreme resistance to a virus resembles immunity to the infection by the virus (Solomon-Blackburn and Barker 2001). The cultivar Atlantic is used as an example of ER to PVX infection in potato. Upon mechanical inoculation, Atlantic plants did not show any visible symptoms or detectable level of PVX (data not shown). In contrast, plants of breeding clone F58050 developed mosaic symptoms and high levels of PVX upon mechanical inoculation (Supplementary Fig. 1B), indicating susceptibility to PVX infection. Further tests on Atlantic plants employing PVX graft-inoculation demonstrated that, even 3 weeks after graft inoculation, no visible symptoms or ELISA-detectable levels of PVX 
$\left(\mathrm{A}_{405}=0.015\right)$ were found in the stock (= Atlantic), whereas high levels of virus $\left(\mathrm{A}_{405}=3.573\right)$ were readily detected in the inoculating scion (= F58050) (Fig. 1). Moreover, daughter plants resulting from tubers of the PVX-graft inoculated Atlantic plants tested PVX free and symptom free (data not shown). Together, these results confirm that Atlantic is extremely resistant or immune to PVX infection.

Using this approach, many breeding clones/cultivars and advanced selections were phenotyped for their reactions to PVX infection within AAFC's potato breeding program as a part of the breeding efforts for developing potato cultivars and superior traits with multiple disease resistances (A. Murphy, personal communication). Table 1 illustrates the response of representative germplasm to PVX infection, the country of origin, as well as the presence/absence of an $R x$ gene in the germplasm.

Assessment of the existing gel electrophoresis-based PCR assays for detection of $R x \boldsymbol{l}$ and $R x \boldsymbol{2}$ and their potential for the gel electrophoresis-free HRM assay in tetraploid potato breeding clones. Marker-assisted selection, either based on indirect detection of $R x$ gene through a molecular marker (e.g., the CAPS marker CP60 DdeI) that is tightly linked to the gene (Bendahmane et al. 1997; Gebhardt et al. 2006) or based on the direct detection of $R x 1$ and/or $R x 2$ (Ahmadvand et al. 2013; Mori et al. 2011), for cultivars with ER to PVX have been reported. As the first step toward implementation of MAS for ER to PVX at AAFC, evaluation of the existing PCR-gel electrophoresis assays for detection of $R x$ gene(s) was performed using representative breeding clones/cultivars (Fig. 2). The primer pair RxSP-S3/RxSPA2 (Mori et al. 2011), which targets the coding region of $R x l$, led to strong amplification of an amplicon of predicted size at 1,230 bp in the resistant clones/cultivars: Rochdale Gold-Dorée, F97050, Atlantic, F87084, Exploits, and Bruza (Fig. 2A, lanes 7 to 12). However, the primers also produced weaker amplification of an amplicon of the same size in PVX-susceptible cultivars/clones: Russet Burbank, Shepody, Yukon Gold, Chieftain, Kennebec, and Green Mountain (Fig. $2 \mathrm{~A}$, lanes 1 to 6 ). The primer pair $5 \mathrm{Rx} 1 \mathrm{~F} / 5 \mathrm{Rx} 1 \mathrm{R}$ (Ahmadvand et al. 2013), which targets the promoter region of $R x 1$, produced an amplicon of predicated size (186 bp) in five resistant clones: Rochdale Gold-Dorée, F97050, Atlantic, F87084, and Exploits (Fig. 2B, lanes 7 to 11). No visible amplification of the predicted amplicon size was observed in the susceptible cultivars: Russet Burbank, Shepody, Yukon Gold, Chieftain, Kennebec, and Green Mountain (Fig. 2B,

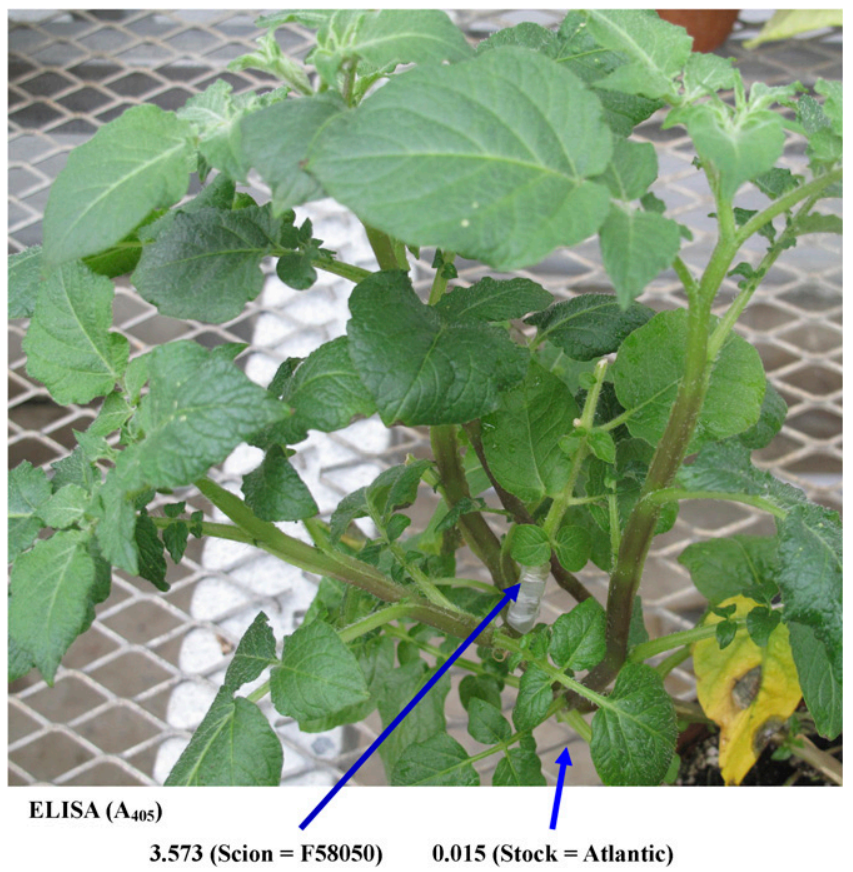

Fig. 1. Response of potato cv. Atlantic to Potato virus $X(P V X)$ after graft inoculation. Enzyme linked-immunosorbent assay (ELISA) testing was performed to detect PVX 3 weeks after graft inoculation. The PVX infected scion (inoculum) was potato clone F58050. Photo was taken 21 days after graft inoculation. lanes 1 to 6 ) as well as the resistant cultivar Bzura that contains $R \times 2$ (lane 12). The primer pair 106Rx2F/106Rx2R (Ahmadvand et al. 2013), which targets the coding region of $R x 2$, led to the amplification of a fragment of predicted size (543 bp) in the resistant clone (cv. Bzura) possessing $R \times 2$ (Fig. 2C, lane 12). It also produced a prominent amplicon of $\sim 480$ bp in Rochdale Gold-Dorée, F97050, Atlantic, F87084, and Exploits (Fig. 2C, lanes 7 to 11). For the susceptible clones, the primer pair also produced a faint fragment at $\sim 543$ bp in the susceptible samples (lanes 1 to 6 ). A recommended duplex PCR with primer pairs $5 \mathrm{R} \times 1 \mathrm{~F} / 5 \mathrm{R} \times 1 \mathrm{R}$ and $106 \mathrm{R} \times 2 \mathrm{~F} /$ 106Rx2R (Ahmadvand et al. 2013) led to a major amplicon (186 bp) projected to be derived from $R x l$ as well as two minor amplicons in the resistant clones Rochdale Gold-Dorée, F97050, Atlantic, F87084, and Exploits (Fig. 2D, lanes 7 to 11), a major amplicon (543 bp) projected to be derived from $R \times 2$, as well as a minor

Table 1. Potato clones/cultivars used for the development of high resolution DNA melting (HRM) for detection of $R x$ genes in tetraploid potatoes

\begin{tabular}{|c|c|c|c|c|}
\hline \multirow[b]{2}{*}{ Potato clone/cultivar } & \multirow{2}{*}{$\begin{array}{l}\text { Country } \\
\text { of origin }\end{array}$} & \multirow{2}{*}{$\begin{array}{l}\text { Response } \\
\text { to } \text { PVX }^{\mathbf{b}}\end{array}$} & \multicolumn{2}{|c|}{$\begin{array}{c}R x \text { presence } \\
(+) / \text { absence }(-)^{c}\end{array}$} \\
\hline & & & Literature & This study \\
\hline AAC Island Ruby & Canada & ER & & $R x 1+, R x 2-$ \\
\hline AC Red Island & Canada & ER & & $R x 1+, R x 2-$ \\
\hline AC Blue Pride & Canada & $S$ & & $R x-$ \\
\hline AC Chaleur & Canada & S & & $R x-$ \\
\hline AC Domino & Canada & ER & & $R x 1+, R x 2-$ \\
\hline Agitato & Germany & ER & & $R x 1+, R x 2-$ \\
\hline Alwara & Germany & ER & $R x 1+{ }^{\mathrm{d}}$ & $R x 1+, R x 2-$ \\
\hline Atlantic & U.S.A. & ER & & $R x 1+, R x 2-$ \\
\hline Barbara & Germany & S & & $R x-$ \\
\hline Bzura & Poland & ER & $R \times 2+{ }^{\mathrm{d}, \mathrm{e}}$ & $R x 1-, R x 2+$ \\
\hline Chieftain & U.S.A. & S & & $R x-$ \\
\hline Exploits & Canada & ER & & $R x 1+, R x 2-$ \\
\hline F10075 & Canada & ER & & $R x 1+, R x 2-$ \\
\hline F02010 & Canada & ER & & $R x 1+, R x 2-$ \\
\hline F58050 & Canada & S & & $R x-$ \\
\hline F58089 & Canada & S & & $R x-$ \\
\hline F59103 & Canada & S & & $R x-$ \\
\hline F79070 & Canada & S & & $R x-$ \\
\hline F87031 & Canada & ER & & $R x 1+, R x 2-$ \\
\hline F87084 & Canada & ER & & $R x 1+, R x 2-$ \\
\hline F97050 & Canada & ER & & $R x 1+, R x 2-$ \\
\hline Green Mountain & U.S.A. & S & & $R x-$ \\
\hline H12581-06 & Canada & ER & & $R x 1+, R x 2-$ \\
\hline Innovator & Netherlands & S & & $R x-$ \\
\hline Jemseg & Canada & ER & & $R x 1+, R x 2-$ \\
\hline Kanona & U.S.A. & $\mathrm{S}$ & & $R x-$ \\
\hline Kennebec & U.S.A. & S & & $R x-$ \\
\hline Mirton Pearl & Canada & S & & $R x-$ \\
\hline MPI63.613/63 & Germany & ER & & $R x 1-, R x 2+$ \\
\hline ND860-02 & U.S.A. & S & & $R x-$ \\
\hline NY121 & U.S.A. & ER & & $R x 1+, R x 2-$ \\
\hline NY123 & U.S.A. & ER & & $R x 1+, R x 2-$ \\
\hline Pirola & Germany & S & & $R x-$ \\
\hline Redsen & U.S.A. & ER & & $R x 1+, R x 2-$ \\
\hline Rochdale Gold-Dorée & Canada & ER & & $R x 1+, R x 2-$ \\
\hline Russet Burbank & U.S.A. & S & & $R x-$ \\
\hline Saco & U.S.A. & ER & & $R \times 1+, R x 2-$ \\
\hline Saikai 35 & Japan & $\mathrm{S}$ & $R x l^{-\mathrm{f}}$ & $R x-$ \\
\hline Shepody & Canada & S & $R x-^{\mathrm{d}}$ & $R x-$ \\
\hline Stobrawa & Poland & ER & & $R x 1-, R x 2+$ \\
\hline Torridon & U.S.A. & ER & & $R x 1+, R x 2-$ \\
\hline Yukon Gold & Canada & S & & $R x-$ \\
\hline
\end{tabular}

a All clones/cultivars with Canada as the country of origin were bred by AAFC's breeding program.

${ }^{\mathrm{b}} \mathrm{ER}$, extreme resistance; $\mathrm{S}$, susceptibility.

${ }^{\mathrm{c}} R x$-, neither $R x 1$ nor $R x 2$ is present.

d Ahmadvand et al. 2013.

e Bendahmane et al. 2000.

${ }^{\mathrm{f}}$ Mori et al. 2011. 
fragment in cv. Bzura (lane 12). Multiple minor amplicons were observed in cvs. Yukon Gold and Green Mountain (lanes 3 and 6). Overall, the simplex PCR with primer pair 5Rx1F/5Rx1R and the duplex PCR with primer pairs 5Rx1F/5Rx1R and 106Rx2F/106Rx2R performed as reported in Ahmadvand et al. (2013). However, simplex PCRs with RxSP-S3/RxSP-A2 (Mori et al. 2011) or 106Rx2F/ 106Rx2R (Ahmadvand et al. 2013), especially the former, did not appear to be specific enough for unambiguous detection of its targeted $R x$ gene.

Development of HRM assay for $R x \boldsymbol{1}$ and $R x \boldsymbol{2}$ in tetraploid potatoes. Even though the PCR assays can detect $R x 1$ and $R x 2$, they cannot differentiate a failed PCR reaction (i.e., $R x 1$ or $R x 2$ is present, but PCR fails) from a susceptible sample (i.e., lack of $R x 1$ or $R x 2$ ). Moreover, the post-PCR procedure requires gel electrophoresis for separation and detection of the amplicons. This extra step not only significantly increases the amount of time but also can potentially introduce errors in the assay. To improve the assay, a primer pair (Rx_S1584, 5'AATGCGTCACACTGGAATTG-3' and Rx_A1756a, 5'-TGAGG GAACAGCTTCTATCG-3') that targets all sequence variants ( $R x 1, R x 2, r x 1$, and $r \times 2)$ corresponding to $R x 1$ 's coding region (nt 1,583 to 1,755 ) was designed (Supplementary Fig. S2). As anticipated, the primer pair produced a fragment of predicted size of $173 \mathrm{bp}$ in all samples regardless of their responses to PVX (Fig. $3 \mathrm{~A}$, upper panel). HRM assay that was conducted following the PCR reaction detected a single melting peak in all the samples (Fig. 3A, bottom panel). When a duplex PCR involving the $R x 1$-specific primer pair 5Rx1F/5Rx1R and the universal primer pair Rx_S1584/ $\mathrm{Rx} \_A 1756$ a was performed, two distinct melting profiles/peaks were detected. One corresponded to the samples (Rochdale Gold-Dorée, F97050, Atlantic, F87084, and Exploits) with Rxl-conferred ER to PVX (Fig. 3B, bottom panel, red line); the other corresponded to the samples that were either susceptible (cv. Russet Burbank, Shepody, Yukon Gold, Chieftain, Kennebec, and Green Mountain) or had Rx2conferred ER to PVX (cv. Bzura) (Fig. 3B, bottom panel, blue line). Gel electrophoresis of the PCR products, on the other hand, detected one visible fragment in all cultivars, even though two amplicons
(173 and $186 \mathrm{bp}$ ) were expected for cultivars Rochdale Gold-Dorée, F97050, Atlantic, F87084, and Exploits (Fig. 3B, upper panel, lanes 7 to 11 , circled in red). This observation was probably due to the low separation capacity of the agarose gel at the concentration used. Indeed, electrophoresis of the amplicons on an $8 \%$ polyacrylamide gel detected two fragments in the samples (data not shown). Triplex PCR involving 5Rx1F/5Rx1R, 106Rx2F/106Rx2R, and Rx_S1584/ Rx_A1756a produced the fragment(s) of $173 / 186$ bp in all cultivars (Fig. 3C, upper panel, lanes 1 to 12). A faint fragment at the predicted size of 543 bp for $R \times 2$ was also visible in cv. Bzura (lane 12, circled in green). HRM assay detected three distinct melting profiles/peaks, representing $R x l$ (red), $r x l$ (blue), and $R x 2$ (green), correspondingly (Fig. $3 \mathrm{C}$, bottom panel), even though the $R \times 2$ melting peak was small.

The duplex PCR-HRM and the triplex PCR-HRM assays were applied to the cultivars/clones listed in Table 1 to determine the presence or absence of $R x 1$ and $R x 2$. Cultivars/clones that tested positive for $R x 1$ included: AAC Island Ruby, AC Red Island, Agitato, Alwara, Atlantic, AC Domino, Exploits, F10075, F02010, F87031, F87084, F97050, H12581-06, Jemseg, NY121, NY123, Rochdale Gold-Dorée, Saco, and Torridon. Bzura, MPI63.613/63, and Stobrawa tested positive for $R x 2$; those testing negative for $R x 1$ and $R \times 2$ included AC Blue Pride, AC Chaleur, Barbara, Chieftain, F58050, F58089, F59103, F79070, Green Mountain, Innovator, Kanona, Kennebec, Mirton Pearl, ND860-02, Pirola, Redsen, Russet Burbank, Saikai 35, Shepody, and Yukon Gold. The presence/absence of an $R x$ gene was consistent with phenotype of the clone.

HRM assay for high throughput detection of $R x 1$ gene in segregating populations and phenotyping of the populations. To test the efficacy of the duplex PCR-HRM detection of $R x 1$ for selection of progeny with ER to PVX, 642 progeny from 12 crosses with at least one Rxl-containing parent were analyzed. As shown in Figure 4, two distinct melting profiles corresponding to $R x l$ (red) and $r x l$ (blue or gray), respectively, were observed in the HRM assays conducted with two different apparatuses and software (Fig. 4A, Bio-Rad CFX96; Fig. 4B, LightScanner) in progeny of Atlantic $\times$ F58050 (Fig. 4A bottom panel left and Fig. 4B left panel: wells 1A
A
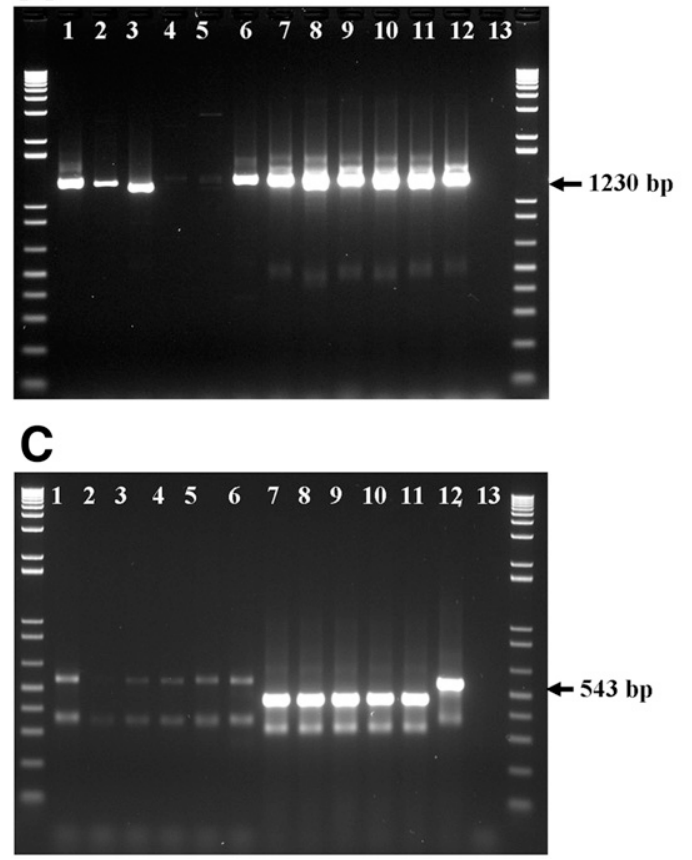

B

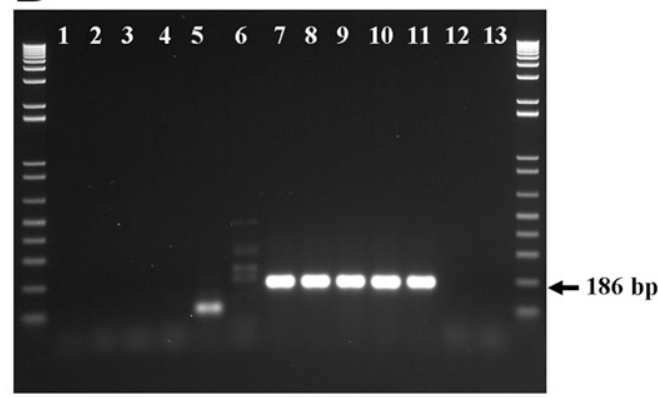

D

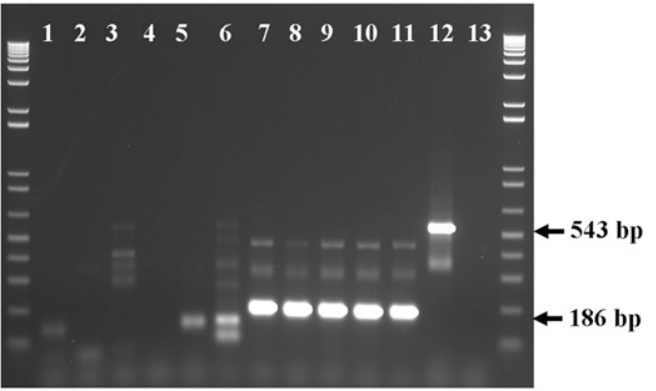

Fig. 2. Assessment of the existing gel electrophoresis-based PCR assays for detection of $R \times 1$ and $R \times 2$ in tetraploid potatoes. A, Simplex PCR for detection of $R \times 1$ using primer pair RxSP-S3/RxSP-A2 reported by Mori et al. (2011). B, Simplex PCR for detection of Rx1 using primer pair 5Rx1F/5Rx1R reported by Ahmadvand et al. (2013). C, Simplex PCR for

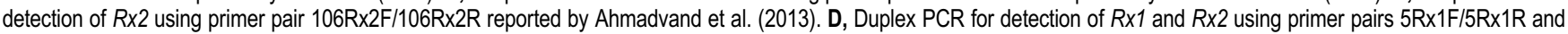
106Rx2F/106Rx2R reported by Ahmadvand et al. (2013). Lanes 1 to 13: Russet Burbank, Shepody, Yukon Gold, Chieftain, Kennebec, Green Mountain, Rochdale Gold-Dorée, F97050, Atlantic, F87084, Exploits, Bruza, and negative (no template) control. The side lanes were the $1 \mathrm{~Kb}$ Plus DNA Ladder (Invitrogen). The amplicon sizes are indicated on the right of the pictures. 
to 4E), Atlantic $\times$ F87031 (Fig. 4A bottom panel left and Fig. 4B left panel: wells $4 \mathrm{~F}$ to $11 \mathrm{C}$ ), and F87084 $\times$ F59012 (Fig. 4A bottom panel left and Fig. 4B left panel: wells $11 \mathrm{D}$ to $11 \mathrm{H}$ ). Identical results were obtained by the CFX96 and the LightScanner assays (Fig. 4). The complete HRM assay for all crosses is summarized in Table 2.
To test whether the HRM assay for $R x l$ can correctly predict the phenotype of the progeny to PVX infection, progeny from 12 crosses were mechanically inoculated with PVX and tested for the virus by ELISA 3 weeks thereafter. All 371 progeny that were identified to possess $R x 1$ by HRM assay were negative by ELISA, confirming
A
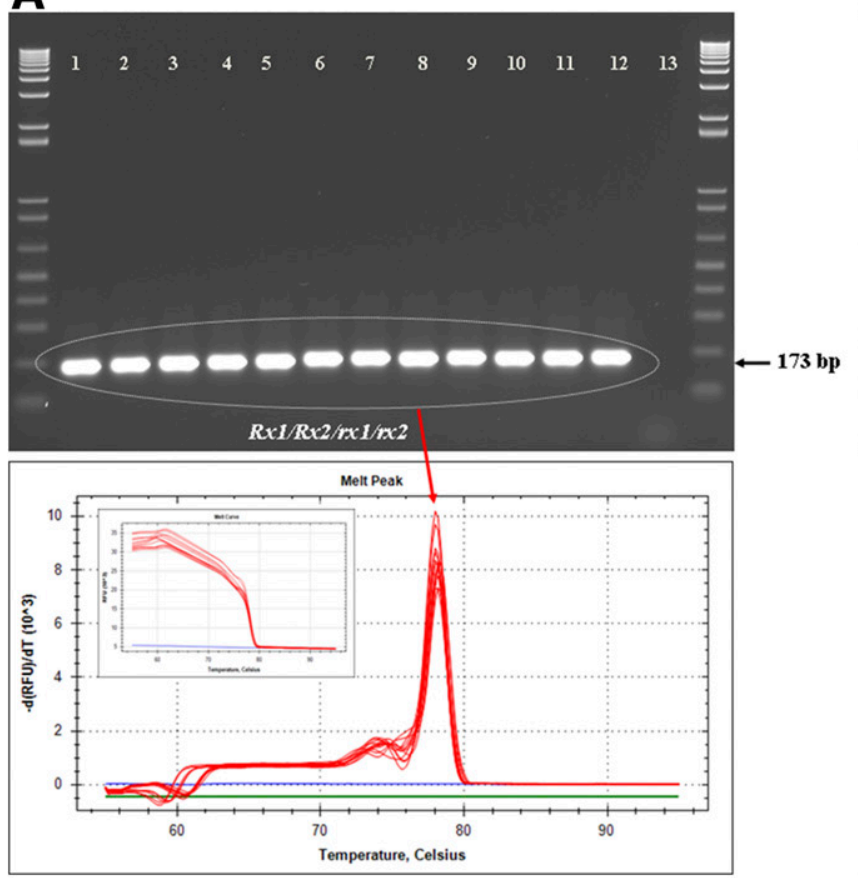

C
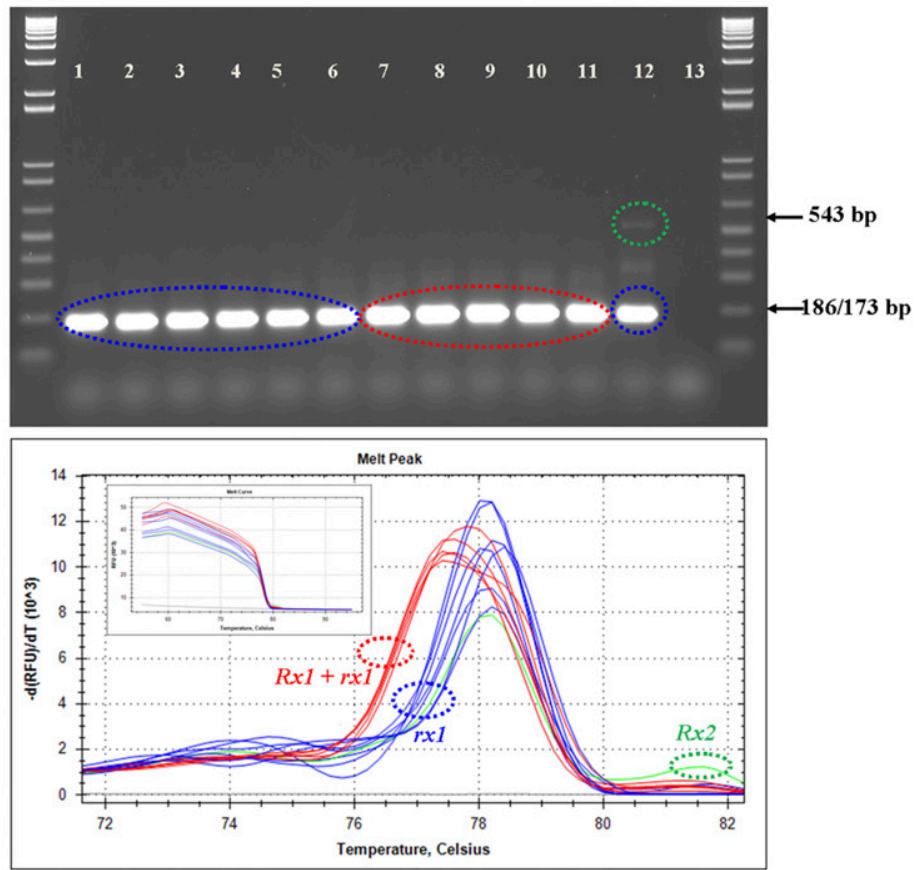

B
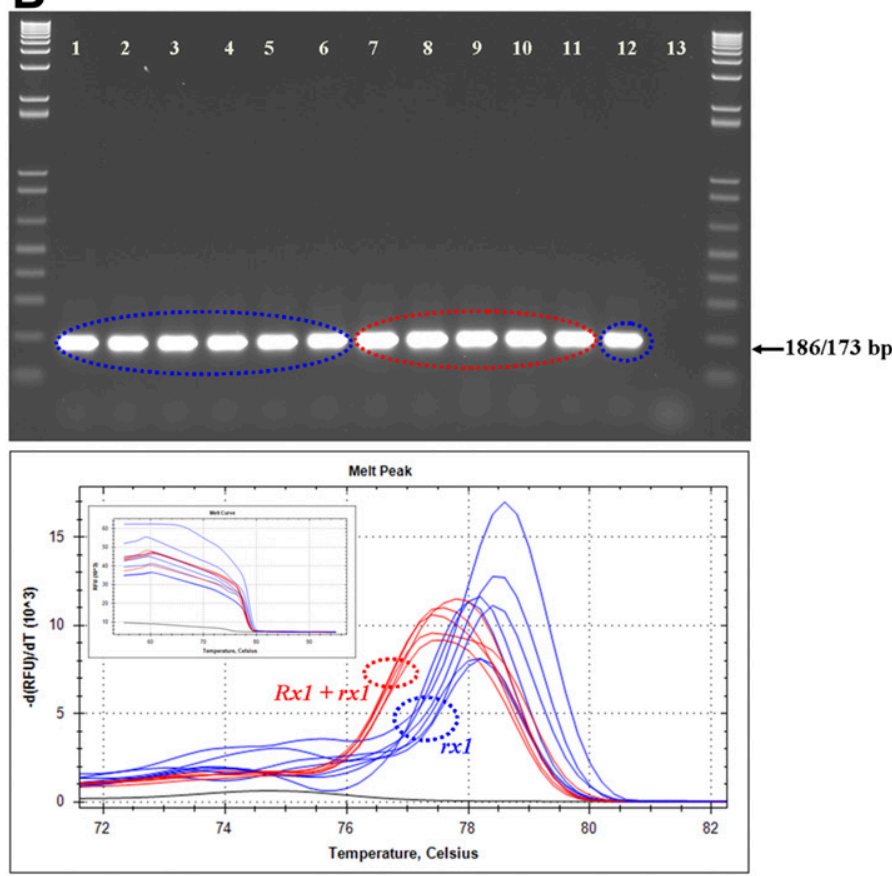

Fig. 3. Development of PCR-high-resolution DNA melting (HRM) assays for detection of $R \times 1$ and $R \times 2$ in tetraploid potatoes. A, Simplex PCR with primer pair Rx_S1584/ Rx_A1756a for detection of all sequence variants $(R \times 1, R \times 2, r \times 1$, and $r x 2)$. B, Duplex PCR with primer pairs Rx_S1584/Rx_A1756a and 5Rx1F/5Rx1R for detection of $R \times 1$. C, Triplex PCR with primer pairs Rx_S1584/Rx_A1756a, 5Rx1F/5Rx1R, and 106Rx2F/106Rx2R for detection of $R \times 1$ and Rx2. After completion of PCR, HRM analysis was performed on CFX96 using the Precision Melt Analysis software. The PCR products were then analyzed using agarose gel electrophoresis. Top panels, agarose gel electrophoresis analysis. Lanes 1 to 13: Russet Burbank, Shepody, Yukon Gold, Chieftain, Kennebec, Green Mountain, Rochdale Gold-Dorée, F97050, Atlantic, F87084 Exploits, Bruza, and negative (no template) control. The side lanes were the $1 \mathrm{~Kb}$ Plus DNA Ladder (Invitrogen). The amplicon sizes are indicated on the right of the pictures. Bottom panels, HRM analysis. The melt peaks as delta relative fluorescent units (RFU) over delta temperature versus temperature ( ${ }^{\circ} \mathrm{C}$ ) are illustrated. Insides are the melt curve data plotted as RFU against temperature $\left({ }^{\circ} \mathrm{C}\right)$. The melting profiles in bottom panels corresponding to their respective amplicons in top panels are indicated by arrow $(A)$ or by color. 
A

$\triangle$ Precision Melt Analysis - 2017-01-30 13-27-29_Plate 5 774-6 \&783-4.melt

File Settings Tools Help

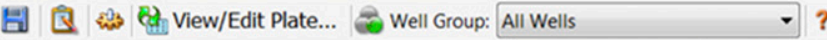

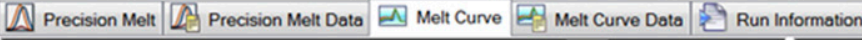
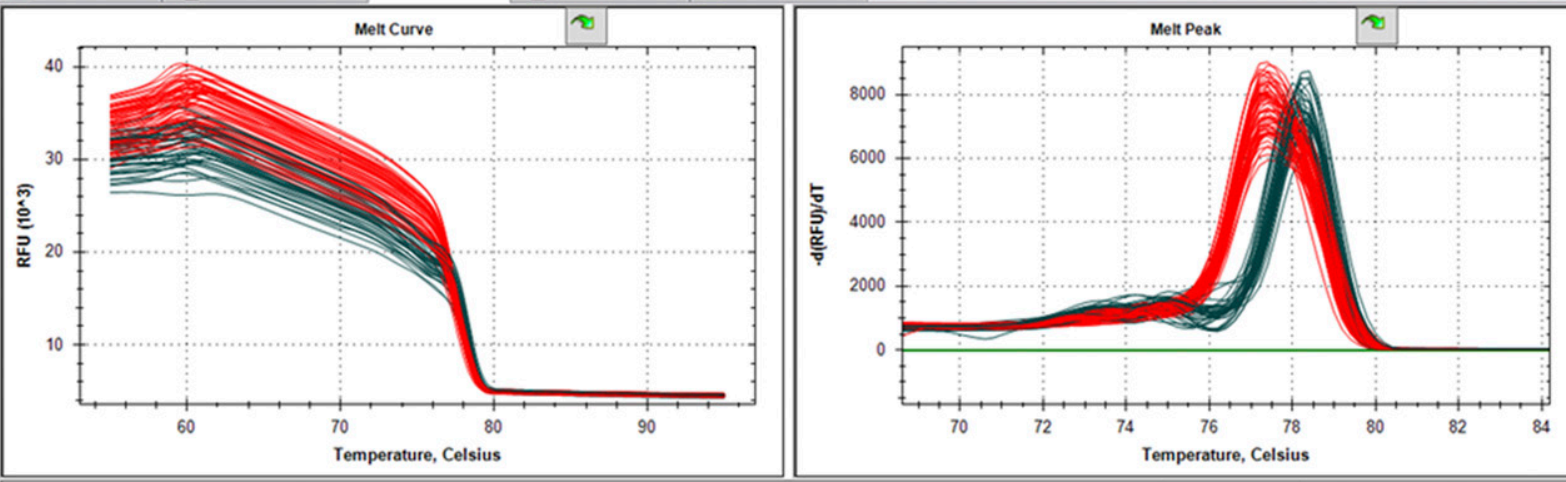

$\nabla$ SYBR

\begin{tabular}{|l|l|l|l|l|l|l|l|l|l|l|l|}
\hline 1 & 2 & 3 & 4 & 5 & 6 & 7 & 8 & 9 & 10 & 11 & 12 \\
\hline
\end{tabular}

Peak Type: Negative Step Number: 9 -

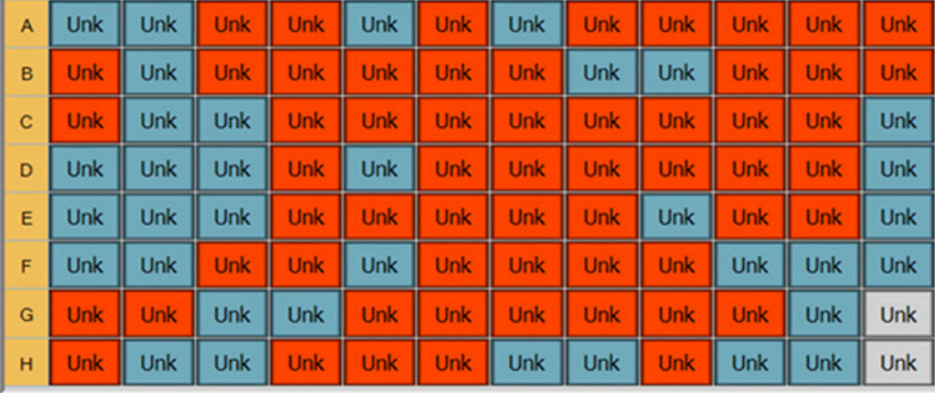

\begin{tabular}{|c|c|c|c|c|c|}
\hline Well ○ & Fluor $\Delta$ & Targe $\Delta$ & Conten $\Delta$ & Somple $\triangle$ & Tem \\
\hline E10 & SYBR & & Unkn & 2429 & 77.20 \\
\hline E11 & SYBR & & Unkn & 2437 & 77.40 \\
\hline E12 & SYBR & SYBR & Unkn & Green Mt ( & 78.20 \\
\hline F01 & SYBR & & Unkn & 2358 & 78.40 \\
\hline F02 & SYBR & & Unkn & 2366 & 78.20 \\
\hline F03 & SYBR & & Unkn & 2374 & 77.40 \\
\hline F04 & SYBR & & Unkn & 2382 & 77.40 \\
\hline F05 & SYBR & & Unkn & 2390 & 78.00 \\
\hline F06 & SYBR & & Unkn & 2398 & 77.40 \\
\hline F07 & SYBR & & Unkn & 2406 & 77.40 \\
\hline F08 & SYBR & & Unkn & 2414 & 77.20 \\
\hline F09 & SYBR & & Unkn & 2422 & 77.40 \\
\hline $\mathrm{F} 10$ & SYBR & & Unkn & 2430 & 78.20 \\
\hline F11 & SYBR & & Unkn & 2438 & 78.00 \\
\hline $\mathrm{F} 12$ & SYBR & SYBR & Unkn & Shepodv & 78.00 \\
\hline
\end{tabular}

\begin{tabular}{l|l} 
Completed & Scan Mode: SYBR/FAM only \\
\hline
\end{tabular}

B

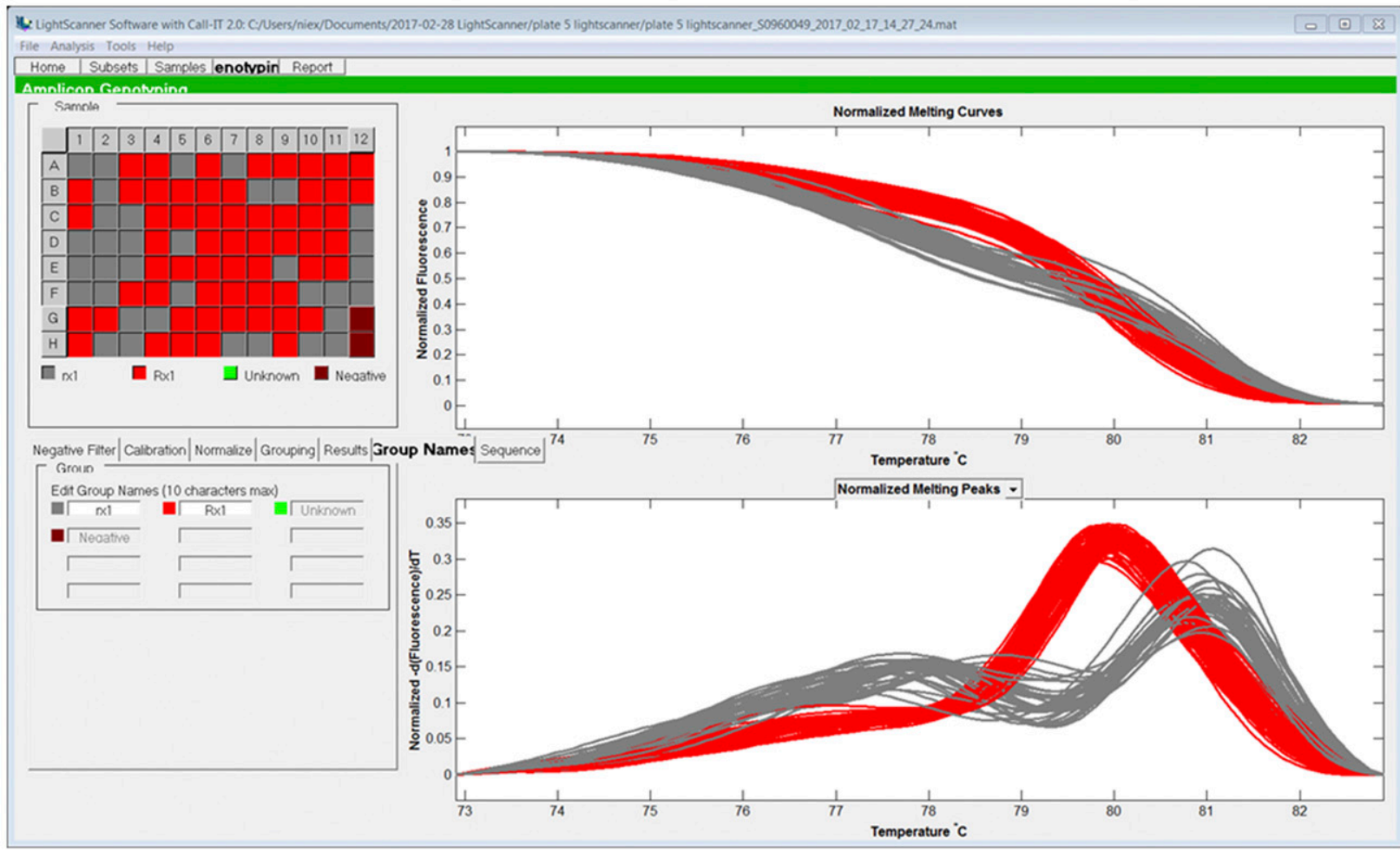

Fig. 4. High-resolution DNA melting (HRM) analysis for detection of $R \times 1$ on segregating populations. A, Analysis carried out on CFX96 with respective software. Graphs were plotted as relative fluorescent units (RFU) against temperature $\left({ }^{\circ} \mathrm{C}\right.$ ) (above left) and the inverse delta of RFU/delta temperature versus temperature $\left({ }^{\circ} \mathrm{C}\right)($ above right). The bottom panel is the genotype summary of the 96-well/sample plate. Red indicates $R \times 1$ (resistant) melting profile and blue indicates $r \times 1$ (susceptible) profile. B, Analysis carried out on LightScanner with respective software. Graphs were plotted as normalized melting curves (above right) and normalized melting peaks (below right) against temperature $\left({ }^{\circ} \mathrm{C}\right)$. The genotype visual summary of the 96-well/sample plate is shown on the left. Red indicates the Rx1 (resistant) melting profile, gray indicates $r \times 1$ (susceptible) melting profile, and brown indicates no-template control. Duplex PCR was performed using primer pairs Rx_S1584/Rx_A1756a and 5Rx1F/5Rx1R. 
resistance of the materials to PVX infection. However, of 271 plants identified as $R x l$-absent, 20 plants, which were scattered in four crosses $(F 87084 \times$ F58050, F87084 × F59103, F87084 × Kanona, and AC Domino $\times$ AC Chaleur), were negative by ELISA assay (Table 2). To test whether these were truly resistant to PVX infection, they were graft-inoculated with PVX-infected scions and tested for the virus 2 weeks thereafter. Of the 31 plants in cross F87084 $\times$ F58050 that had tested PVX-negative after mechanical inoculation, 26 remained to be PVX-negative whereas five tested PVX-positive by ELISA after graft-inoculation, agreeing with the HRM assay. Similarly, the remaining plants that had tested PVX-negative but $R x l$-absent were PVX-positive after graft-inoculation, thus matching with the HRM assay. Together, the HRM assay for $R x l$ is in complete agreement with the phenotyping results. It is interesting to note that some of the PVX-susceptible plants (i.e., ELISA positive) in these four crosses developed local and/or systemic necrosis after mechanical inoculation, which contrasted with their parents upon PVX infection. The unexpected induction of necrosis by PVX infection in some of the progeny might have interfered with viral establishment, thus leading to underestimation of susceptible plants.

Analysis of the populations for segregation indicated a simplex Rxl in all resistant parents, all but one $(\mathrm{F} 87084 \times$ F59103, $\left.\chi^{2}=8.6471, P=0.0032\right)$ fitting either a $1: 1$ (resistant/susceptible) ratio for crosses involving a resistant parent and a susceptible parent (AC Chaleur $\times$ F02010, $\chi^{2}=1.1852, P=0.2763$; AC Blue Pride $\times$ Redsen, $\chi^{2}=0.4545, P=0.5002 ; \mathrm{F} 87084 \times \mathrm{F} 58050, \chi^{2}=0.0000$, $P=1$; Torridon $\times$ AC Blue Pride, $\chi^{2}=0.1636, P=0.6859$; NY121 $\times$ ND860-02, $\chi^{2}=0.1636, P=0.6859$; Atlantic $\times$ F58089, $\chi^{2}=0.8909, P=0.3452 ;$ F87084 $\times$ Kanona, $\chi^{2}=0.0800, P=$ 0.7773; Mirton Pearl $\times$ Rochadale Gold-Dorée, $\chi^{2}=0.4545, P=$ 0.5002; AC Domino $\times$ AC Chaleur, $\chi^{2}=0.2963, P=0.5862$ ) or a 3:1 ratio for crosses involving two resistant parents (Torridon $\times$ Redsen, $\chi^{2}=2.3595, P=0.1245$; Atlantic $\times$ F87031, $\chi^{2}=0.2970, P=$ 0.5858 ) (Table 3 ). The genotype of the parents of these populations was also determined.

\section{Discussion}

Despite the advantages of marker-assisted selection over phenotypic selection, including the increased selection efficiency and precision, application of MAS in plant breeding is still relatively low (Xu and Crouch 2008). Among the reasons that hinder the implementation of MAS are user friendliness, throughput capacity, and cost effectiveness. Depending on the marker type, it may involve multiple steps after DNA extraction and normally requires gel electrophoresis,

Table 2. High resolution DNA melting (HRM) assay for Rxl and phenotyping for extreme resistance to Potato virus $X$ (PVX) in segregating tetraploid potato populations $^{\mathrm{a}}$

\begin{tabular}{|c|c|c|c|c|c|c|c|c|c|}
\hline \multirow{2}{*}{\multicolumn{2}{|c|}{ Parents }} & \multirow{2}{*}{\multicolumn{2}{|c|}{ HRM }} & \multirow{2}{*}{\multicolumn{2}{|c|}{$\begin{array}{l}\text { ELISA- } \\
\text { PMC }\end{array}$}} & \multirow{3}{*}{$\begin{array}{c}\text { Total number of } \\
\text { discrepancies between } \\
\text { HRM and ELISA-PMC }\end{array}$} & \multicolumn{3}{|c|}{ ELISA-PGC } \\
\hline & & & & & & & \multirow{2}{*}{$\begin{array}{l}\text { Number of plants } \\
\text { graft-inoculated }\end{array}$} & \multirow[b]{2}{*}{ Neg. } & \multirow[b]{2}{*}{ Pos. } \\
\hline Female & Male & $R x 1$ presence & $\overline{R x I}$ absence & Neg. & Pos. & & & & \\
\hline AC Chaleur (S) & F02010 (R) & 31 & 23 & 31 & 23 & 0 & $\ldots$ & $\ldots$ & $\ldots$ \\
\hline AC Blue Pride (S) & Redsen (R) & 25 & 30 & 25 & 30 & 0 & $\ldots$ & $\ldots$ & $\ldots$ \\
\hline $\mathrm{F} 87084(\mathrm{R})$ & F58050 (S) & 26 & 26 & 31 & 21 & 5 & $31^{\mathrm{c}}$ & 26 & 5 \\
\hline Torridon (R) & Redsen (R) & 43 & 8 & 43 & 8 & 0 & $\ldots$ & $\ldots$ & $\ldots$ \\
\hline Torridon (R) & AC Blue Pride (S) & 29 & 26 & 29 & 26 & 0 & $\ldots$ & $\ldots$ & $\ldots$ \\
\hline NY121 (R) & ND860-02 (S) & 29 & 26 & 29 & 26 & 0 & $\ldots$ & $\ldots$ & $\ldots$ \\
\hline Atlantic (R) & F58089 (S) & 24 & 31 & 24 & 31 & 0 & $\ldots$ & $\ldots$ & $\ldots$ \\
\hline Atlantic (R) & F87031 (R) & 43 & 12 & 43 & 12 & 0 & $\ldots$ & $\ldots$ & $\ldots$ \\
\hline F87084 (R) & F59103 (S) & 36 & 15 & 39 & 12 & 3 & $3^{\mathrm{d}}$ & 0 & 3 \\
\hline F87084 (R) & Kanona (S) & 26 & 24 & 34 & 16 & 8 & $8^{\mathrm{d}}$ & 0 & 8 \\
\hline Mirton Pearl (S) & $\begin{array}{l}\text { Rochdale } \\
\text { Gold-Dorée (R) }\end{array}$ & 30 & 25 & 30 & 25 & 0 & $\cdots$ & $\ldots$ & $\ldots$ \\
\hline AC Domino (R) & AC Chaleur (S) & 29 & 25 & 33 & 21 & 4 & $4^{\mathrm{d}}$ & 0 & 4 \\
\hline Total & & 371 & 271 & 391 & 251 & 20 & 46 & 26 & 20 \\
\hline
\end{tabular}

a PMC, postmechanical inoculation; PGC, postgraft inoculation; neg., negative; pos., positive.

${ }^{\mathrm{b}}$ Discrepancy between HRM assay and enzyme-linked immunosorbent assay (ELISA) is defined by the negative test for PVX by ELISA and the absence of RxI by HRM assay.

c All progeny plants that tested negative for PVX by ELISA after mechanical inoculation were graft-inoculated with PVX.

d Progeny plants that tested negative for PVX by ELISA and the absence of Rxl by HRM assay were graft-inoculated with PVX.

Table 3. Segregation of extreme resistance conferred by $R x 1$ to Potato virus $X$ in crosses involving various tetraploid potato parental clones ${ }^{\mathrm{a}}$

\begin{tabular}{|c|c|c|c|c|c|c|c|c|c|c|c|c|c|}
\hline & & & & \multicolumn{8}{|c|}{ Expected } & \multirow{2}{*}{\multicolumn{2}{|c|}{$\begin{array}{l}\text { Projected genotype } \\
\text { of the parents }\end{array}$}} \\
\hline \multicolumn{2}{|c|}{ Parents } & \multicolumn{2}{|c|}{ Observed } & \multicolumn{4}{|c|}{ 1:1 } & \multicolumn{4}{|c|}{$3: 1$} & & \\
\hline Female & Male & $\mathbf{R}$ & $\mathbf{S}$ & $\mathbf{R}$ & $\mathbf{S}$ & $\chi^{2}$ & $P$ & $\mathbf{R}$ & $\mathbf{S}$ & $x^{2}$ & $P$ & Female & Male \\
\hline AC Chaleur (S) & F02010 (R) & 31 & 23 & 27 & 27 & 1.1852 & 0.2763 & 40.5 & 13.5 & $8.9136^{*}$ & 0.0028 & rxIrxIrxIrxI & RxIrxIrxIrxI \\
\hline $\begin{array}{l}\text { AC Blue } \\
\text { Pride (S) }\end{array}$ & Redsen (R) & 25 & 30 & 27.5 & 27.5 & 0.4545 & 0.5002 & 41.25 & 13.75 & $25.6061^{*}$ & $<0.00001$ & rxIrxIrxIrxI & RxIrxIrxIrxI \\
\hline F87084 (R) & F58050 (S) & 26 & 26 & 25.5 & 25.5 & 0.0000 & 1 & 39 & 13 & $17.3333 *$ & $3.1 \mathrm{E}-05$ & RxIrxIrxlrxl & rxlrxlrxlrxl \\
\hline Torridon (R) & Redsen (R) & 43 & 8 & 25.5 & 25.5 & $24.0196 *$ & $<0.00001$ & 38.25 & 12.75 & 2.3595 & 0.1245 & RxIrxIrxIrxl & RxIrxIrxIrxI \\
\hline Torridon (R) & $\begin{array}{l}\text { AC Blue } \\
\text { Pride (S) }\end{array}$ & 29 & 26 & 27.5 & 27.5 & 0.1636 & 0.6859 & 41.25 & 13.75 & $14.5515^{*}$ & 0.000136 & RxIrxlrxlrxl & rxIrxlrxIrxI \\
\hline NY121 (R) & ND860-02 (S) & 29 & 26 & 27.5 & 27.5 & 0.1636 & 0.6859 & 41.25 & 13.75 & $14.5515^{*}$ & 0.000136 & RxIrxIrxIrxl & rxlrxlrxlrxl \\
\hline Atlantic (R) & F58089 (S) & 24 & 31 & 27.5 & 27.5 & 0.8909 & 0.3452 & 41.25 & 13.75 & $28.8545^{*}$ & $<0.00001$ & RxIrxIrxIrxl & rxlrxIrxlrxl \\
\hline Atlantic (R) & F87031 (R) & 43 & 12 & 27.5 & 27.5 & $17.4727 *$ & $2.9 \mathrm{E}-05$ & 41.25 & 13.75 & 0.2970 & 0.5858 & RxIrxIrxIrxl & RxIrxIrxIrxI \\
\hline F87084 (R) & F59103 (S) & 36 & 15 & 25.5 & 25.5 & $8.6471 *$ & 0.0032 & 38.25 & 12.75 & $0.5294^{\mathrm{a}}$ & 0.4669 & RxIrxIrxIrxI & rxIrxIrxIrxI \\
\hline F87084 (R) & Kanona (S) & 26 & 24 & 25 & 25 & 0.0800 & 0.7773 & 37.5 & 12.5 & $14.1067 *$ & 0.000173 & RxIrxlrxlrxl & rxlrxlrxlrxl \\
\hline Mirton Pearl (S) & $\begin{array}{l}\text { Rochdale Gold- } \\
\text { Dorée (R) }\end{array}$ & 30 & 25 & 27.5 & 27.5 & 0.4545 & 0.5002 & 41.25 & 13.75 & $12.2727 *$ & 0.00046 & rxIrxIrxIrxI & RxIrxIrxIrxI \\
\hline AC Domino (R) & AC Chaleur (S) & 29 & 25 & 27 & 27 & 0.2963 & 0.5862 & 40.5 & 13.5 & $13.0617 *$ & 0.000302 & RxIrxIrxIrxI & rxlrxlrxlrxl \\
\hline
\end{tabular}

a The R:S ratio of $\sim 3: 1$ was likely caused by distorted segregation ratio. ${ }^{*}$, Significant at $P<0.01 ; \mathrm{R}$, resistant; S, susceptible. 
thus limiting its capacity to handle large numbers of samples (Nie et al. 2016). The HRM assay, on the other hand, increases the detection efficiency dramatically by analyzing the amplicon melting profile immediately after a PCR reaction without any handling of PCR products. It not only eliminates the post-PCR handling of the PCR products (e.g., cleavage of amplicon, gel-electrophoresis) but also enhances the detection accuracy as the potential error-prone deciphering of target fragments from gel electrophoresis analysis is unnecessary. As demonstrated previously (Nie et al. 2016), by converting the gel electrophoresis-based STS markers YES3-3A and YES3-3B for $R y_{\text {sto }}$ to HRM markers, a dramatic increase in efficiency was achieved. Simultaneous detection of up to 96 samples by HRM assay for detection of a $R y_{\text {sto }}$ marker can be completed in less than 10 min following PCR amplification, thus saving several hours over the conventional gel electrophoresis-based post-PCR detection of the STS markers. Keeping this in mind, we evaluated the efficacy of currently available PCR-gel electrophoresis assays, adopted the primers that are suitable for HRM detection of the target $R x$ amplicon, and furthermore, developed a duplex-PCR HRM for high-throughput detection of the presence or absence of $R x l$ in potato. By using the HRM assay in combination with the KingFisher 96-well plate DNA extraction procedure, a robust DNA extraction platform that allows up to 96 samples to be simultaneously extracted in $\sim 3 \mathrm{~h}, \sim 280$ samples can be assessed for the presence and absence of $R x l$ in 3 days. This is a dramatic increase in efficiency for MAS for the target trait. The method is user friendly and can be performed by less experienced personnel such as university summer/co-op students. Further savings of time and expense can be achieved by utilizing the same DNA extracts for screening other traits for which HRM markers are available. In AAFC's breeding program as well as other breeding programs in the U.S.A., resistances to several major diseases/pests including PVX, PVY, and the potato cyst nematode (PCN) are routinely screened (A. Murphy, personal communication). The same set of DNA can be used for high-throughput HRM assays for the haplotype TG689 marker linked to the PCN resistance gene $H 1$ (De Koeyer et al. 2010), the YES3 markers linked to $R y_{\text {sto }}$ (Nie et al. 2016), and $R x l$ (this study), thus increasing the selection efficiency greatly by saving 6 to 9 months of time over the phenotypic screening of three different traits for the same number (i.e., 280) of plants/progeny. Similarly, HRM markers for quality traits could be applied to the extracted DNA samples.

The testing of the HRM assay for $R x l$ in 12 segregating populations demonstrated its superior accuracy, as it correctly predicted the phenotype of 642 progeny plants from 12 crosses. This is manifested by the complete consistency between the presence/absence of $R x l$ determined by HRM assay and the PVX infection determined by ELISA upon mechanical inoculation in eight out of 12 populations. Moreover, the HRM assay correctly predicted the ultimate phenotype of 20 progeny from four crosses that tested $R \times 1$-absent, yet ELISAnegative after mechanical inoculation, as PVX susceptible. Together, the HRM assay for $R x l$ is in complete agreement with the phenotype in all 642 progeny from 12 crosses.

Although it is considered to be time-, labor-, and space-consuming, phenotyping of PVX resistance of potato is straightforward and normally reliable due to the mechanical transmission mode of PVX by nature (Slack 2001). A susceptible plant can be readily infected with the virus through mechanical wounding, and indeed, upon mechanical inoculation, the susceptible progeny from eight out of 12 crosses were infected with PVX. All the infected materials lacked visible necrosis. In contrast, some PVX susceptible progeny from the remaining four crosses (i.e., F87084 × F58050, F87084 × F59103, F87084 × Kanona, AC Domino $\times$ AC Chaleur) developed local and/or systemic necrosis after mechanical inoculation even though none of the parents (F87084, F58050, F59103, Kanona, AC Domino, and AC Chaleur) developed such symptoms upon mechanical and/or graft-inoculation. It suggests that an $N$ gene ( $N x$ or $N b$ ) is likely present in the $R x 1$-possessing parents. When both $R x$ and the $N$ gene are present, the function of $N$ is epistatic to $R x$, and the plant is unable to be infected with PVX and no visible symptoms will be incited upon either mechanical or graftinoculation. A similar phenotype is anticipated for a plant that contains $R x$ but not $N$. In the case when $R x$ is absent, the symptomatic expression/phenotypic reaction of a plant to PVX infection depends on the presence/absence of $N$ : when $N$ is present, $N$-mediated hypersensitive resistance (HR), a partial resistance against PVX, occurs, and the plant develops local and/or systemic lesions; when $N$ is absent, systemic infection takes place in the plant, and no necrosis occurs. Based on this hypothesis, the resistant parents F87084 and AC Domino likely contain an $N$ gene in addition to $R x l$. This hypothesis not only explains the occurrence of necrosis in response to PVX infection in some of the progeny from crosses involving F87084 or AC Domino as a parent, but also explains the underestimation of susceptible plants upon mechanical inoculation. The presence of the $N$ gene in the $R x$-absent progeny triggers $\mathrm{HR}$, which in turn interferes with the establishment of PVX, leading to ELISA-negative results from these plants 2 weeks after mechanical inoculations. However, upon PVX graft-inoculation, the plants tested positive for the virus. Two $N$ genes, i.e., $N x$ and $N b$, have been identified (Santa Cruz and Baulcombe 1995) on chromosome 9 (Tommiska et al. 1998) and chromosome 5 (De Jong et al. 1997; Marano et al. 2002), respectively. Further research is needed to determine whether and which $N$ gene is present in F87084 and AC Domino.

Previously, F87084, a breeding clone that possesses multiple resistances including ER to PVX, PCN, and PVY (De Jong et al. 2001; Nie et al. 2015), has been proposed to have an $R x$ in duplex condition (De Jong et al. 2001). The source of the $R x$ in F87084 has been traced to the S. tuberosum subsp. andigena CPC 1673 (De Jong et al. 2001), which is in agreement with the $R x l\left(=R x_{a d g}\right)$ identity determined in this study. However, based on the segregation data obtained from both $R x 1$-HRM assay and phenotypic analysis in three crosses involving F87084 as a parent $(\mathrm{F} 87084[\mathrm{R}] \times \mathrm{F} 58050[\mathrm{~S}], \mathrm{F} 87084$ $[\mathrm{R}] \times \mathrm{F} 59103$ [S], F87084 [R] $\times$ Kanona [S]), the $R x$ in F87084 is more likely in a simplex condition. The discrepancy between this study and that of De Jong et al. (2001) regarding the dosage of $R x$ in F87084 could be at least partially attributed to the interference of phenotyping by $N x$ - or $N b$-mediated HR against PVX, as the segregation analysis by De Jong et al. was based exclusively on the phenotypic data. Nevertheless, distorted segregation ratios might have also contributed to the possible overestimation of Rxl dosage, as evidenced by the close to 3:1 (R/S) segregating ratio in cross F87084 (R) $\times$ F59103 (S).

It is also worthwhile to note that 1) $R x l$ is present more widely than $R x 2$ in potato germplasm in AAFC's potato breeding program, and 2) all PVX-resistant parents analyzed in this study contain a simplex $R x 1$.

\section{Acknowledgments}

The authors would like to thank Angela Gallagher for ELISA testing and Donna Wilson for much of the PVX phenotyping of the parental materials. The authors also acknowledge the assistance of the AAFC-Fredericton Research and Development Centre field staff at Benton Ridge and the greenhouse staff at Fredericton for the cultivation of the test materials. This research was funded by AAFC under the peer-reviewed projects \# J-000991

\section{Literature Cited}

Ahmadvand, R., Wolf, I., Gorji, A. M., Polgár, Z., and Taller, J. 2013. Development of molecular tools for distinguishing between the highly similar $R x 1$ and $R x 2$ PVX extreme resistance genes in tetraploid potato. Potato Res. 56:277-291.

Bendahmane, A., Kanyuka, K., and Baulcombe, D. C. 1997. High-resolution genetical and physical mapping of the $\mathrm{Rx}$ gene for extreme resistance to potato virus X in tetraploid potato. Theor. Appl. Genet. 95:153-162.

Bendahmane, A., Kanyuka, K., and Baulcombe, D. C. 1999. The $R x$ gene from potato controls separate virus resistance and cell death responses. Plant Cell 11:781-791.

Bendahmane, A., Querci, M., Kanyuka, K., and Baulcombe, D. C. 2000. Agrobacterium transient expression system as a tool for the isolation of disease resistance genes: application to the $R \times 2$ locus in potato. Plant J. 21: 73-81.

Brown, C. R., and Corsini, D. L. 2001. Genetics and breeding of virus resistance: traditional methods. Pages 323-340 in: Viruses and virus-like disease of potato. G. Loebenstein, P. Berger, A. A. Brunt, and R. H. Lawson, eds. Kluwer Academic Publishers, Dordrecht, The Netherlands.

Cockerham, G. 1943. The reactions of potato varieties to viruses X, A, B and C Ann. Appl. Biol. 30:338-344.

De Jong, H., Proudfoot, K. G., and Murphy, A. M. 2001. The germplasm release of F87084, a fertile, adapted clone with multiple disease resistances. Am. J. Potato Res. 78:141-149. 
De Jong, W., Forsyth, A., Leister, D., Gebhardt, C., and Baulcombe, D. C. 1997. A potato hypersensitive resistance gene against potato virus $\mathrm{X}$ maps to a resistance gene cluster on chromosome 5. Theor. Appl. Genet. 95:246-252.

De Koeyer, D., Douglass, K., Murphy, A., Whitney, S., Nolan, L., Song, Y., and De Jong, W. 2010. Application of high-resolution DNA melting for genotyping and variant scanning of diploid and autotetraploid potato. Mol. Breed. 25:67-90.

Gebhardt, C., Bellin, D., Henselewski, H., Lehmann, W., Schwarzfischer, J., and Valkonen, J. P. T. 2006. Marker-assisted combination of major genes for pathogen resistance in potato. Theor. Appl. Genet. 112:1458-1464.

Heldák, J., Brutovská, E., and Galliková, A. 2009. Selection of valuable potato genotypes with introduced resistance genes derived from wild species. Agriculture (Pol'nohospodárstvo) 55:133-139.

Hooker, W. J., Peterson, C. E., and Timian, R. G. 1954. Virus X resistance in potato. Am. Potato J. 31:199-212.

Kanyuka, K., Bendahmane, A., Van Der Voort, J. R., Van Der Vossen, E. A. G., and Baulcombe, D. C. 1999. Mapping of intra-locus duplications and introgressed DNA: aids to map-based cloning of genes from complex genomes illustrated by physical analysis of the $R x$ locus in tetraploid potato. Theor. Appl. Genet. 98:679-689.

MacLachlan, D. S., Larson, R. H., and Walker, J. C. 1954. Potato virus A. Am. Potato J. 31:67-72.

Marano, M., Malcuit, I., De Jong, W., and Baulcombe, D. 2002. High-resolution genetic map of $\mathrm{Nb}$, a gene that confers hypersensitive resistance to potato virus $\mathrm{X}$ in Solanum tuberosum. Theor. Appl. Genet. 105:192-200.

Mori, K., Sakamoto, Y., Mukojima, N., Tamiya, S., Nakao, T., Ishii, T., and Hosaka, K. 2011. Development of a multiplex PCR method for simultaneous detection of diagnostic DNA markers of five disease and pest resistance genes in potato. Euphytica 180:347-355.

Nie, X., Liang, Z., Nie, B., Murphy, A., and Singh, M. 2015. Studies on varietal response to different strains of Potato virus $Y$ (PVY) reveal hypersensitive resistance in Exploits to $\mathrm{PVY}{ }^{\mathrm{O}}$ and extreme resistance in F87084 to all tested strains. Am. J. Potato Res. 92:23-31.
Nie, X., and Singh, M. 2013. Response of potato, tobacco and Physalis floridana plants to mixed infection with PVX, PVY ${ }^{\mathrm{NTN}}$ and PVY ${ }^{\mathrm{O}}$ strains. Can. J. Plant Pathol. 35:390-401.

Nie, X., Sutherland, D., Dickison, V., Singh, M., Murphy, A. M., and De Koeyer, D. 2016. Development and validation of high-resolution melting (HRM) markers derived from $R y_{\text {sto }}$ STS markers for high-throughput marker-assisted selection of potato carrying $R y_{\text {sto }}$. Phytopathology 106:1366-1375.

Querci, M., Baulcombe, D. C., Goldbach, R. W., and Salazar, L. F. 1995. Analysis of the resistance-breaking determinants of potato virus $\mathrm{X}(\mathrm{PVX})$ strain $\mathrm{HB}$ on different potato genotypes expressing extreme resistance to PVX. Phytopathology 85:1003-1010.

Ritter, E., Debener, T., Barone, A., Salamini, F., and Gebhardt, C. 1991. RFLP mapping on potato chromosomes of two genes controlling extreme resistance to potato virus X (PVX). Mol. Gen. Genet. 227:81-85.

Santa Cruz, S., and Baulcombe, D. 1995. Analysis of potato virus X coat protein genes in relation to resistance conferred by the genes $N x, N b$ and $R x l$ of potato. J. Gen. Virol. 76:2057-2061.

Sathuvalli, V., Brown, C. R., Yilma, S., Charlton, B. A., Shock, C. C., Quick, R., Feibert, E., Whitworth, J. L., Novy, R. G., Stark, J. C., Pavek, M. J., Knowles, N. R., Navarre, R. A., Debons, J., and Vales, M. I. 2016. Yukon Nugget: a midseason yellow skin, yellow flesh specialty potato with extreme resistance to Potato Virus X. Am. J. Potato Res. 93:602-608.

Slack, S. A. 2001. Potato virus X. Page 69 in: Compendium of Potato Diseases, 2nd Ed., W. R. Stevenson, R. Loria, G. D. Franc, and D. P. Weingartner, eds. APS Press, St. Paul, MN.

Solomon-Blackburn, R., and Barker, H. 2001. Breeding virus resistant potatoes (Solanum tuberosum): A review of traditional and molecular approaches. Heredity 86:17-35.

Tommiska, T. J., Hämäläinen, J. H., Watanabe, K. N., and Valkonen, J. P. T. 1998. Mapping of the gene $N x_{p h u}$ that controls hypersensitive resistance to potato virus X in Solanum phureja lvP35. Theor. Appl. Genet. 96:840-843.

$\mathrm{Xu}$, Y., and Crouch, J. H. 2008. Marker-assisted selection in plant breeding: from publications to practice. Crop Sci. 48:391-407. 